\title{
Study on thermal deformation behavior of Cu-Zr-Ce alloy
} TIAN Ka ${ }^{1, a}$, TIAN Baohong ${ }^{2, b}$, LIU Yong ${ }^{2, c}$, ZHANG Yi $^{2, d}$, SONG Kexing ${ }^{3, e}$

$\left({ }^{1}\right.$ College of Materials Science and Engineering, Henan University of Science and Technology, Luoyang 471023, China, ${ }^{2}$ Collaborative Innovation Center of Nonferrous Metals, Luoyang 471023, China, ${ }^{3}$ Henan Key Laboratory of Non-ferrous Materials Science and Technology, Luoyang 471023 , China)

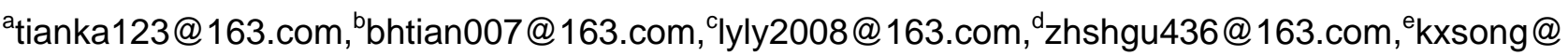
haust.edu.cn

Keywords: Cu-Zr-Ce alloy, flow stress, constitutive equation, thermal activation energy Abstract. The flow stress curves of $\mathrm{Cu}-1.0 \% \mathrm{Zr}-0.15 \% \mathrm{Ce}$ alloy during high temperature deformation were analyzed by using a Gleeble-1500D thermal simulation machine at the hot deformation temperature of $550{ }^{\circ} \mathrm{C}, 650^{\circ} \mathrm{C}, 750{ }^{\circ} \mathrm{C}, 850{ }^{\circ} \mathrm{C}$ and $900{ }^{\circ} \mathrm{C}$, the strain rate of $0.001 \mathrm{~s}^{-1}$ 、 $0.01 \mathrm{~s}^{-1} 、 0.1 \mathrm{~s}^{-1} 、 1 \mathrm{~s}^{-1} 、 10 \mathrm{~s}^{-1}$, respectively. The results show that the hot deformation mechanism of the alloy is mainly based on the dynamic recovery under relative lower hot deformation temperature or higher strain rate. The thermal deformation mechanism of the $\mathrm{Cu}-1.0 \% \mathrm{Zr}-0.15 \% \mathrm{Ce}$ alloy is the dynamic recrystallization under relative higher hot deformation temperature or lower strain rate. The constitutive equation of the alloy was calculated and established respectively on the basis of the relationships among the flow stress, strain rates and deformation temperature. The thermal activation energy of the alloy is about $430.51 \mathrm{~kJ} / \mathrm{mol}$.

\section{Introduction}

Pure copper has high electrical conductivity, thermal conductivity and excellent processing performance, which has been widely used in industry ${ }^{[1]}$. With the rapid development of industrial technology, pure copper is limited due to its relative lower strength, lower recrystallization temperature and other shortcomings ${ }^{[2]}$. Determining how to ensure high conductivity and excellent mechanical properties is the focus of high strength and high conductivity copper alloys. The published research results show that the addition of trace $\mathrm{Zr}$ can significantly improve the strength, softening temperature and wear resistance of copper alloy ${ }^{[3-6]}$. Cu-Zr alloys are usually applied in thermal radiation, thermal shock and intensive heat exchange environment, the performance of the alloy is closely related to its thermal behavior ${ }^{[7-9]}$. Therefore, it is important to study the thermal deformation behavior of the $\mathrm{Cu}-\mathrm{Zr}$ alloys, which is to provide the basis data of its thermal processing technology and for the safe operation during hot wok processes.

In this paper, the thermal-mechanical simulation experiments of $\mathrm{Cu}-1.0 \% \mathrm{Zr}-0.15 \% \mathrm{Ce}$ alloy were carried out. The thermal deformation activation energy of the alloy was calculated by the relationship among the deformation, strain rates and deformation temperature, which provide reference for practical production process of the alloy.

\section{Experiment}

The feed stocks used in the experiment are 99.95wt\% (mass fraction) standard cathode copper, the purity of $99.5 \%$ pure $\mathrm{Zr}$ in block shape and the purity Ce of $20 \% \mathrm{Cu}-\mathrm{Ce}$ intermediate alloy. The alloy was fabricated in a ZG-0.01-40-4 type vacuum intermediate frequency induction furnace. The chemical composition of the $\mathrm{Cu}-1.0 \% \mathrm{Zr}-0.15 \% \mathrm{Ce}$ alloy is as follows, $1.0 \% \mathrm{wtZr}, 0.15 \mathrm{wt} \% \mathrm{Ce}$, and $\mathrm{Cu}$, balanced. After removal riser of the alloy casting ingot, the alloy ingot was extruded into rod of $\phi 33 \mathrm{~mm}$ in diameter with an XJ-500 model extrusion machine. The extrusion rod was solid solution treated at $900{ }^{\circ} \mathrm{C}$ for 1 hour. The specimen was processed into cylinder of $\phi 8 \mathrm{~mm} \times 12 \mathrm{~mm}$ in size. The isothermal compression experiments were performed in a Gleeble-1500D thermal simulator system. The test parameters are as follows: compression temperature of $550{ }^{\circ} \mathrm{C} 、 650{ }^{\circ} \mathrm{C} 、 750{ }^{\circ} \mathrm{C}$ 、 
$850{ }^{\circ} \mathrm{C} 、 900{ }^{\circ} \mathrm{C}$ and the strain rates of $0.001 \mathrm{~s}^{-1} 、 0.01 \mathrm{~s}^{-1} 、 0.1 \mathrm{~s}^{-1} 、 1 \mathrm{~s}^{-1} 、 10 \mathrm{~s}^{-1}$, respectively. The compression deformation is about $55 \%$ in total. The heating rate is $10^{\circ} \mathrm{C} / \mathrm{s}$ and the holding time is 6 min. After hot compression, the specimen was water quenched to preserve the microstructure at high temperature.

\section{Results and Analysis}

Flow stress analysis of $\mathbf{C u - 1 . 0 \% Z r - 0 . 1 5 \% C e ~ a l l o y . ~ F i g . ~} 1$ is the true stress and true strain curves of $\mathrm{Cu}-1.0 \% \mathrm{Zr}-0.15 \% \mathrm{Ce}$ alloy during hot compression deformation. It can be seen from Fig. 1, when the strain rate is constant, the higher the deformation temperature is, the smaller the corresponding flow stress is. When the deformation temperature is constant, the higher the strain rate is, the higher the corresponding flow stress is. This indicates that the flow stress of the alloy is significantly affected by the strain rates and deformation temperature. In the initial stage of thermal deformation, the flow stress of the alloy increases sharply due to the increasing of true strain. With the increasing of true strain, the flow stress occurs in three cases. The first one is that the flow stress slowly rises corresponding to the deformation hardening mechanism, the second one is slowly declines corresponding to dynamic recrystallization mechanism, and the third one is maintain stable to a certain value corresponding to dynamic recovery mechanism. These indicate that the alloy has more complicated thermal deformation mechanism.

At the beginning of the hot deformation, the lattice distortion of the alloy is caused by the grain deformation so that the dislocation density increases rapidly. For further deformation the dislocation tangles occur, which produce hardening phenomenon. At lower deformation temperature, ranging from $550{ }^{\circ} \mathrm{C}$ to $750{ }^{\circ} \mathrm{C}$ showed in Fig. 1(a)-(c), or under the condition of high strain rate, ranging from $1 \mathrm{~s}^{-1}$ to $10 \mathrm{~s}^{-1}$ showed in Fig. 1(c)-(d), the internal stress in deformed alloy accumulates to a certain extent resulting in occurrence of dynamic recovery. The dislocation density of the alloy decreases showing a slow increase in the true stress and true strain curves, showed in the $550^{\circ} \mathrm{C}$ in Fig. 1(d). While at higher deformation temperature or under the condition of lower strain rate, the hot deformation process is accompanied by the formation and growth of the dynamic recrystallization nucleation. The softening rate of the alloy is larger than that of the strain hardening rate, in which the true stress and true strain curves decreases , showed in Fig. 1 (a) at $750^{\circ} \mathrm{C}$. As the deformation hardening rate is equivalent to the dynamic recovery and dynamic recrystallization rate, the true stress and true strain curves tend to be steady, showed in Fig. 1(c) at $650^{\circ} \mathrm{C}$. The main reason for the above changing rules is the competing result of dynamic thermal processing of strain hardening and dynamic softening of recovery and recrystallization simultaneously. 

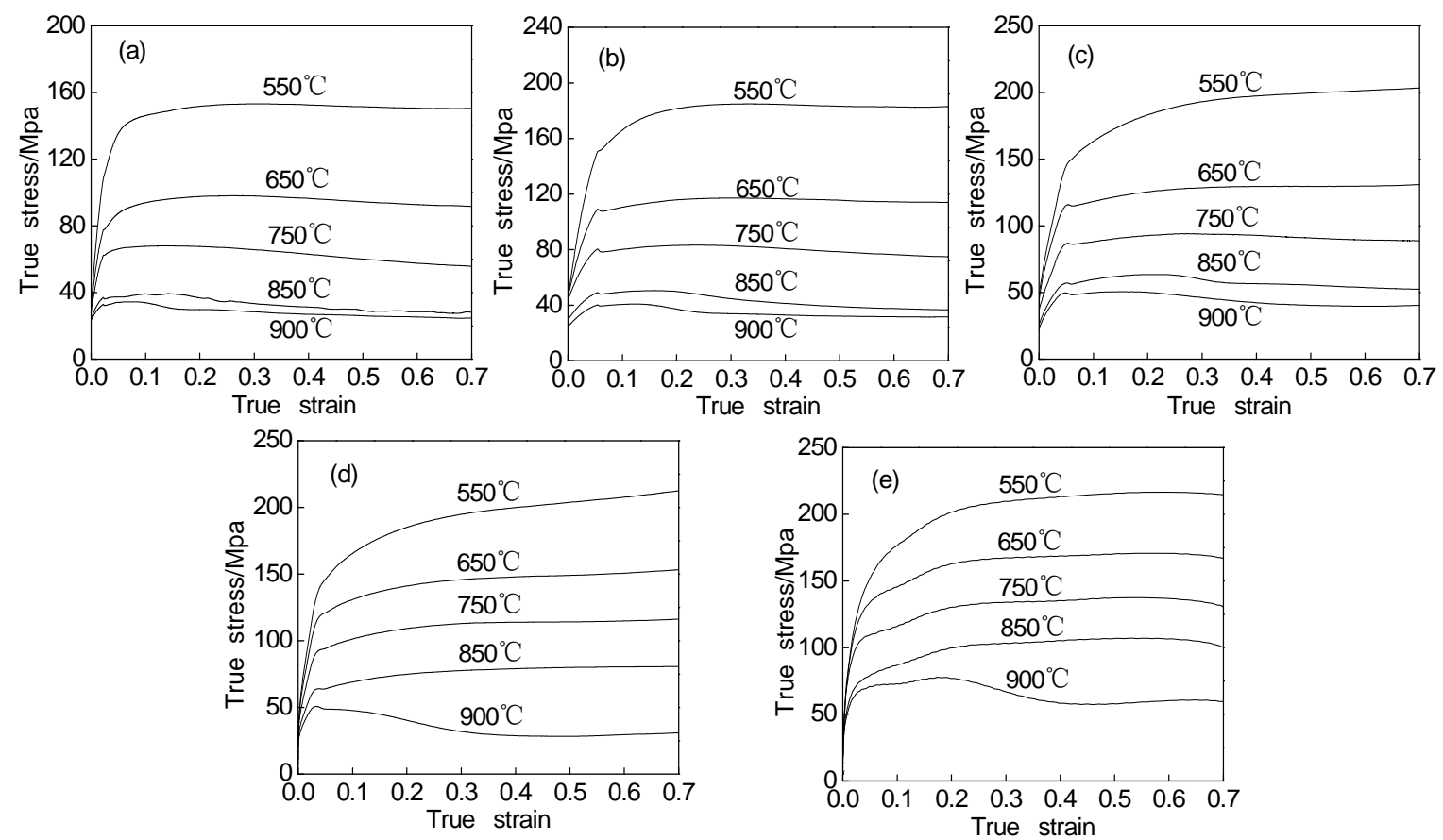

Fig. 1 True stress and true strain curves of Cu-1.0\%Zr-0.15\%Ce alloy at different temperature and strain rates
(a) $\dot{\varepsilon}=0.001 \mathrm{~s}^{-1}$;
(b) $\dot{\varepsilon}=0.01 \mathrm{~s}^{-1}$;
(c) $\dot{\varepsilon}=0.1 \mathrm{~s}^{-1}$;
(d) $\dot{\varepsilon}=1 \mathrm{~s}^{-1}$;
(e) $\dot{\varepsilon}=10 \mathrm{~s}^{-1}$

Constitutive equation of $\mathrm{Cu}-1.0 \% \mathrm{Zr}-\mathbf{0 . 1 5 \% C e}$ alloy.The hot plastic deformation process at elevated temperature of metallic material is similar to that of high temperature creep process, both of which are thermal activation processes. The flow stress depends on the deformation temperature $T$ and strain rate $\dot{\varepsilon}^{[10]}$. A mathematical model for describing the flow stress of metals at high temperature deformation is described by using the function of Zener-Hollomon parameters, as follows ${ }^{[11,12]}$ :

$$
Z=A[\sinh (\alpha \sigma)]^{n}
$$

Where $A$ is a structural factor, $n$ is the stress exponent, $\alpha$ is the stress level parameter, it can be defined as the $\mathrm{Z}$ parameter.

$$
Z=\dot{\varepsilon} \exp \left(\frac{Q}{R T}\right)
$$

Where $Q$ is the thermal activation energy, $R$ is the molar gas constant.

Replace the formula (2) into the equation (1), the strain rate is describes as following,

$$
\dot{\varepsilon}=A[\sinh (\alpha \sigma)]^{n} \exp \left(-\frac{Q}{R T}\right)
$$

Take the partial derivative of the formula (3) , the Q is expressed as following,

$$
Q=\left.\left.R \frac{\partial \ln [\sinh (\alpha \sigma)]}{\partial(1 / T)}\right|_{\dot{\varepsilon}} \cdot \frac{\partial \ln \dot{\varepsilon}}{\partial \ln [\sinh (\alpha \sigma)]}\right|_{T}
$$

In order to get the accurate constitutive equation of the alloy, the values of $A, n, \alpha$ and $Q$ were determined on the basis of above results. According to the experimental data and the linear regression analysis showed in Fig. 2, the values of the above parameters can be obtained as following, $A=1.22 \times 10^{20}, n=9.59, Q=430.51 \mathrm{~kJ} / \mathrm{mol}, \alpha=0.011$. Therefore, the constitutive equation of the $\mathrm{Cu}-1.0 \% \mathrm{Zr}-0.15 \% \mathrm{Ce}$ alloy is expressed as following,

$$
\dot{\varepsilon}=1.22 \times 10^{20}[\sinh (0.011 \sigma)]^{9.59} \exp \left(-\frac{430.51 \times 10^{3}}{R T}\right)
$$



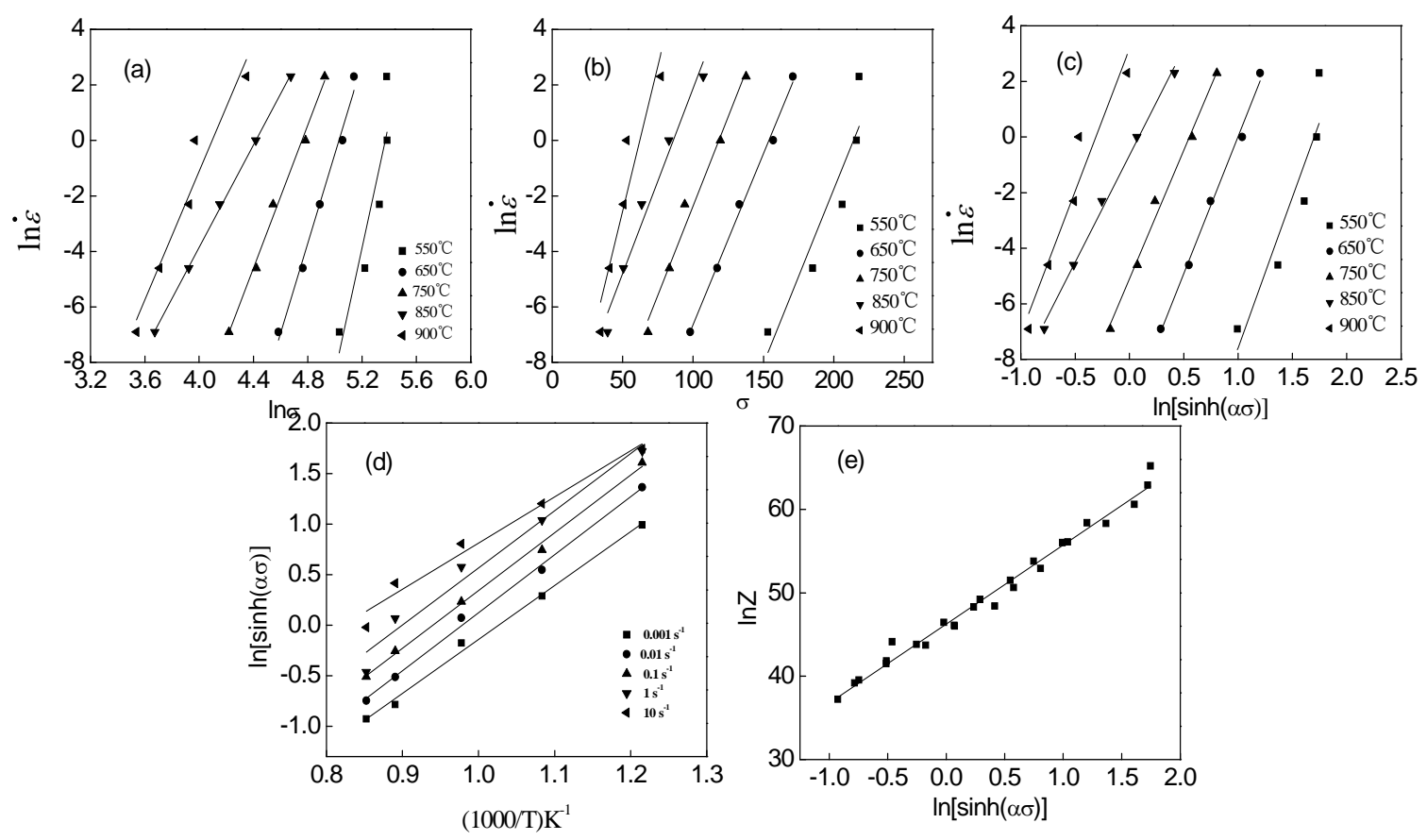

Fig. 2 Relationships among peak flow stress, deformation temperature and strain rate of $\mathrm{Cu}-1.0 \% \mathrm{Zr}-0.15 \%$ Ce alloy

(a) $\ln \dot{\varepsilon}-\ln \sigma$, (b) $\ln \dot{\varepsilon}-\sigma$, (c) $\ln \dot{\varepsilon}-\ln [\sinh (\alpha \sigma)]$, (d) $\ln [\sinh (\alpha \sigma)]-1 / T$, (e) $\ln Z-\ln [\sinh (\alpha \sigma)]$

\section{Conclusions}

(1) The strain rate and deformation temperature have significant effects on the flow stress of the $\mathrm{Cu}-1.0 \% \mathrm{Zr}-0.15 \% \mathrm{Ce}$ alloy. When the loading rate of the stress is constant, the higher hot deformation temperature is, the smaller corresponding flow stress is. When the hot deformation temperature is constant, the higher strain rate is, the higher corresponding flow stress is.

(2) The thermal activation energy of $\mathrm{Cu}-1.0 \% \mathrm{Zr}-0.15 \% \mathrm{Ce}$ alloy is $430.51 \mathrm{~kJ} / \mathrm{mol}$, and the constitutive equation of the thermal deformation of the alloy is obtained as follows,

$$
\dot{\varepsilon}=1.22 \times 10^{20}[\sinh (0.011 \sigma)]^{9.59} \exp \left(-\frac{430.51 \times 10^{3}}{R T}\right)
$$

\section{Acknowledgements}

This work was financially supported by the National Natural Science Foundation of China (51101052). Sponsored by Program for Science and Technology Innovation Talents in Universities of Henan Province (14IRTSTHN007) .

\section{References}

[1] Zhimin Yin, Shenglong Zhang. Metallurgical Engineering, 2002,22 (2): 1-5.

[2] Bing Wen. Chengdu: Sichuan University, 2007: 8.

[3] Shuguo Jia, Ping Liu, Maosheng Zheng. Functional Materials, 2007,38: 494-496.

[4] Ping Liu, Shuguo Jia, Maosheng Zheng. Journal of Materials Research, 2006,20 (1): 109-112.

[5] J .P. Tu,W .X. Qi, Y. Z. Yang. Wear, 2002(249):1021-1027.

[6] Dongmei Zhao, Qiming Dong, Ping Liu, Zhihao Jin, Buxi Kang. The Chinese Journal of 
Nonferrous Metals, 2001, S2: 21-24.

[7] E. Bayraktar, R. Mora, I.M. Garcia, C. Bathias. International Journal of Fatigue 2009, 31 (10) : 1532.

[8] H.T. Yao, F.Z. Xuan, Z.D. Wang, S.T. Tu. Nuclear Engineering and Design 2007, 237: 1969.

[9] Weiping Gan, Yiren Wang, Tieping Chen, Fuliang Yang,Hong Liu. Material Review, 2006, 05: 111-113.

[10] Ruilong Zhao, Yong Liu, Baohong Tian, Xiaowei Zhang, Yi Zhang. Heat Treatment of Metals, 2011, 08: 17-20.

[11] H. J. Mcqueen, S. Yue, N.D. Ryan. Mater Process Technology, 1995, 53: 293-310.

[12] C. Zener, J.H. Hollomon. Appl Phys, 1944, 15(1): 22-27. 